\title{
An Interview with David Harvey
}

Stephen Pender, University of Windsor

\section{Introduction}

"There is a far, far nobler prospect of freedom to be won than that which neoliberalism preaches. There is a far, far worthier system of governance to be constructed than that which neoliberalism allows." So ends David Harvey's A Brief History of Neoliberalism (Oxford, 2005), a book in which he historicizes neoliberal thought, pillories neoliberal policy, and excoriates neoliberals themselves for celebrating social and economic practices that fail the vast majority of people. On September 25, 2006 David Harvey visited the University of Windsor to speak about "Neoliberalism and the City."

Harvey (b. 1935) was educated at Cambridge and has taught at several institutions, notably Oxford, Johns Hopkins University, and now the Graduate Centre at the City University of New York. His publications include Social Justice and the City (1973), The Limits to Capital (1982), The Condition of Postmodernity (1989), considered one of the most important works of non-fiction published since 1945 and, more recently, The New Imperialism (2003) and A Brief History of Neoliberalism (2006). Over dinner and wine, though it was not quite vinum daemonum, Harvey spoke with Stephen Pender, director of the Humanities Research Group and associate professor of English, University of Windsor.

Stephen Pender: What is the relationship between activism and the academy?

David Harvey: I start with a material base, which is that I have a job in the academy that is my point of production. What do I do there? I engage in the production and reproduction of knowledge. This site, the academy, is contested; increasingly, the academy is being subjected to neoliberal disciplinary apparatuses of various kinds. It is also becoming a place where neoliberal ideas are being spread. So the first point I want to make is that I have a crucial role to play in trying to resist the neoliberalization of the academy, which is largely about organizing within the academy. I think that it is really very wrong for people to think that just because you are organizing with the academy, you are just an academic and you are not politically active. In fact, a lot of my political life has been given over to creating spaces within the academy, where things could be said, written, discussed, and ideas promulgated. Right now those spaces are more under threat then they have been in many years ... so part of my activism is dedicated to that.

SP: The university is often figured as immured from "external” politics, at least by those on the outside looking in. Is the academy somehow separate from its social context? Is academic work political work?

DH: If you want to open spaces in universities, one of the things you have to do is to 
acknowledge that they set the rules, so you have to play by their rules. To some degree, this does compromise you, no question about it. When I started out, most of the people I knew as radicals got fired from academia because they did not follow the rules. So I played by the rules to some degree. Some people would say, my radical students would say, "you compromised far too much," and maybe that's true. On the other hand, I did open up spaces, partly by being academically respectable as well as radical. That is a compromised position, I know, but it is strategically adopted for certain political purposes. I'm fighting this battle inside academia, others are fighting it in healthcare, and others still are fighting it in the steel works. So, to me, we have to think about constructing alliances, between people who are struggling at all the different points of production. We have to articulate what we have in common and the ways in which we might support each other. Now, I've never taken the idea that just because I am an academic I know better than they do; I've never accepted that idea. I've always taken the idea I want them to help me organize and I can help them organize, at the same time I can help them see things that they don't see. Since I know how to write, how to do things, I want to use that power, not to represent what people say, but to magnify their voice, in a way that other people are going to hear it. So one becomes a kind of echo chamber, for what you hear from people in a living wage campaign, or whatever. You want to become an echo chamber by sending it out to a larger audience. For me, political activism is being very active where I'm at, but also about establishing alliances and having the possibility to magnify the voices around me. I am not a good organizer, I am not a good militant in the sense that I can be out on the streets. I am good at certain things, and I try to use those skills in a very specific way to be as active as I can. I treat it as part of a much larger process, and I hope people will see it as a significant part. I would never make the claim that this was somehow the heart of the process; it is just a part.

SP: With that in mind, has your conception of social justice changed from your early excursions and interventions in the 1970s to now? If so, how?

DH: Well there's one sense in which it hasn't changed, which is that I always saw social justice not as a universal or absolute, but as something that was always contingent upon the circumstances in which you were working; of course, the circumstances in which I was working in the early 1970s are very different from now. Therefore, you have to articulate ideas about social justice now in ways which are very different from 30 years ago. On that, I think I would argue that we made certain suppositions 30 years ago about the political situation; we even believed we would actually transform the world in a radical kind of way - we actually believed we could construct a socially-just society. We thought there was a revolution around the corner - and it's very hard to say to people now, that that was the situation in which we were formulating our ideas. At that point, we could take ideas that seemed almost like absolute ideals because we felt the contingent situation was such that we could realize it.

SP: Praxis, as one might say.

DH: Yeah, now that's all gone. I mean, you talk to many people, and most will figure that there is no alternative to things as they are. So what you are trying to do is use the idea of social justice to mobilize people, to understand the world in a different way. So it becomes a strategic idea, the idea of justice becomes part of trying to 
awaken thoughts, rather than complete them, as was the case in the early 1970s. From that standpoint, injustice becomes the topic of conversation; now, injustice is what we talk about. We don't have a positive conception of justice; we have a negative conception of lack of justice - injustice. That is a very important mobilizing idea. So I think that's a big, big, difference about how we use the idea. However, the circumstances are such that none of us imagine that we are going to take power tomorrow, whereas in the 1970s, a lot of people in social movements, political movements really thought that power was within our grasp and I think one of the things we need to talk about is what did we do wrong in the 1970s, when power in some respects was indeed within our grasp, and we let it slip. And why did we let it slip? How did we let it slip?

SP: Was it apocalyptic thinking? Was it millenarian thinking? Was it too much of the "liberate our desire and we shall be free?" What was the mistake?

DH: I don't know; I think "the mistake” was a multitude of things. Let's face it; in the 1970s the Communist Party was near to power in France and Italy, there was a revolution in Portugal, and revolutions throughout much of the developing world. As an urbanist, for a model, I always go back to Red Bologna, a great example of how communism can really work on the ground. We were beginning to break loose of the Soviet Union, so you had euro-communism, things like that. But I think the left at that moment actually became very conservative; many hung on to the gains of the 1960s rather than say "we're prepared to give that up, for a higher purpose" - but nobody actually knew what that purpose was, which is what the Labour Party ran into in Britain in the mid-1970s. What was the corporatist response to the crisis on the left?

So I think there were many things that went wrong and, again, I think that we need to evaluate that period; and without such detailed evaluation, I don't have a clear answer. We are moving towards a point of crisis ourselves in the next five to ten years, and I think the left has to know that we're not going to do that again, we are not going to loose it that way again.

SP: In part, I think, the New Left underestimated the rise of neo-conservatism in the US. As US hegemony is challenged by the spatial and economic orders you are at pains to identify and describe, neoconservatives turn to morality as a form of hectoring, and as means of justification for both internal and external coercion. As the US economic power, and its ability to wield such power, wanes, its leadership turns to the comforting panaceas of liberal democracy to underwrite its efforts; is this the future for what might be called "moral imperialism" or mitigated imperialism? Is democracy the final stick with which to beat those the US cannot bring to heel with capital? Are these moral as well as political questions?

DH: Perhaps I should go back and show how I define the neoconservative project, which is not only about the mobilisation of moral authority; it's also about the imposition of order, a militaristic sense of order. I don't think democracy is what they are about at all. I think the only democracy they have in mind is the kind of democracy that exists in the US, which is the democracy of money and raw military power. My view of them is best described, I think, by Karl Rove's dream, to have the US follow China. We have a one party system called the "Republucrats"; beneath it you have a raging, completely unregulated capitalism. This is generating enormous 
amounts of wealth, which is being accumulated by a few people at the top of the system. That is what is happening in China to some extent with the authoritarian structure there and this is what I think they have in mind. To mobilize that, I think neoconservative morality is not just simply an abstract morality; it is hierarchical. And since it is hierarchical, then it is always therefore about the hierarchal imposition of order. I think you have to ask yourself, what is the big distinction between the Bush Administration and the Clinton Administration? Clinton for me was the quintessential neoliberal; what Bush objected to was the lack of moral principle and lack of order.

SP: And this is what distinguishes neoconservativism from neoliberalism?

DH: Yes. Neoconservatives are not against the market system, but they want it to be like China. Underneath this, I think, is their hatred of Clinton; and this is what always bothered me - I could never understand why the right was so apoplectic about Clinton when he was doing all the right neoliberal things. He came in promising universal healthcare and he gave us NAFTA, the WTO, and welfare "reform." He did all the things we would expect a good neoliberal to do. But the right loathed him still, and I think it is because their utopian vision of the world is order, morality, and then the crazy market can do what it wants. So I think that is how I would conceptualize the problem.

SP: You have made sophisticated arguments about the relationship between capitalism, space, and imperialism, particularly in your Oxford lectures on "the new imperialism." You write with vigour about US hegemony, particularly in the Middle East, and specifically in Iraq; in that context, you mention potential US aggression against Iran. Can you explain your current perspective on what you have called the US' "own distinctive form of imperialism," perhaps with specific reference to Iran?

DH: I think the US was very concerned to dominate not only Iraq, but Iran. But this is the point where I must introduce some simple geography: I don't think Bush thought that the distinction between Sunnis and Shiites was any different than that between Methodists and Baptists. I don't think Bush understood anything about the dynamics of that region. I think Bush had the fantasy that you invade Iraq and everybody greets you with great pleasure and immediately the population of Iran will clamour to be liberated also. I think we have to understand that the geographical world these people inhabit has not necessarily anything to do with the reality. My analogy is Christopher Columbus. Columbus arrived in the Americas, not knowing where he was, and having no idea about the world he encountered. He totally messed up almost everything in the Americas. Celebrated as a great explorer, Columbus was a lousy geographer, and Bush and Cheney are lousy geographers, and anthropologists. They don't know what is going on, why it is going on, or where it is going on. So I think we should not always attribute to them some grand design with perfect knowledge of the situation. They have a grand design, but almost no knowledge about the situation. I met somebody once who went down to the State Department over the Iranian issue, because he knew a lot about Iran. He sat down with the so called experts in the State Department — it was a high level meeting — and he asked them, "how long have you spent in Iran?" Two weeks. "Do you know the language?” No. "What do you know of the history?” Well I know about the Shah. At this point, I think we need to recognize that actually a lot of these things are profound 
geographical mistakes. Behind them lurks the idea that if they can democratize the region, neoliberalize the region, not only will the oil flow freely, they will have huge markets. There are 50 million people in Iran; this is a big potential market, and a sophisticated, educated populace there, with a lot of potential to develop. So you can see it as a potential entrepreneurial paradise for global capitalism ... they probably had that idea about it too, but they didn't understand these complexities. They even forgot that Iran and Iraq fought a war for eight or nine years, in which there were a million casualties on the Iranian side. Everybody knows that Iraq was supported by the US; everybody knows in Iran that Iraq waged germ warfare and the US never uttered a sound. They are only doing it now in order to go after Saddam; this is the sort of thing you need to look at.

SP: Certain strains of post-war Anglo-American Marxism have attempted to think through problems of base and superstructure, and the problems with that ossified metaphor, by attending to culture as a constituent element of material life [I have Raymond Williams in mind, for example]. What is the role of culture in your work? How should contemporary Marxist and Marxian intellectuals envision culture? Was Williams right about the role of culture in the production and reproduction of material life? How might, as Williams put it, literature teach feeling?

DH: There is as Raymond Williams would say "a lot of confusion about the word culture." It conveys an enormous amount of differential roots and meanings. I happen to work in an anthropology program, where the concept of culture is very different from literary studies and the rest of the humanities. So I have to signal that problem from the onset. Having said that, I want to say something which to me is very important; this is a line from Gramsci in The Prison Notebooks: "when political questions are transformed to cultural issues, they become unanswerable." I think Williams and Stuart Hall and the like, attempted to find political content in cultural questions, that is, to take Gramsci at his word, and try to find the politics. I think in a lot of cultural studies it's been read the other way - that you can't go anywhere unless you're prepared to take the political issue and make it cultural. From an anthropological perspective, I would say that that is a ridiculous manoeuvre on the part of people in the humanities, because from an anthropological or geographical perspective, you try to work through the whole nature of material culture, symbolic culture, and all the rest of it. If you're really political, what you are looking for is the political way in which this comes together so programmatically, in some sort of attempt to transform the world. So I take this as part of what I would consider my mission: what I try to do, for instance in The Condition of Postmodernity, is argue that everybody is talking about the cultural world, but what I want to talk about is "what is the political economy that lies behind all of this?” When we get to the political economy, we ask ourselves a question, "are you simply about changing the culture, or are you about changing the political economy?”

On that point, I would go back to what we were talking about earlier; I think the big failure of the left over the last 200 years has been to define an alternative political economy to capitalism. I am told frequently that our big failure is that we didn't take culture into account. I'm saying, “no," we can take that into account as much as we want, and I think some of us use some very sophisticated ways to take it into account. Until we come up with an alternative political economic system, we're 
badly off. We have never been able to define that; so, instead of more cultural analysis, we need more solid political economic analysis.

SP: What do you say, then, to activists and revolutionaries who argue that a particular political order depends on the exigencies of that particular moment? They argue that such a system cannot be envisioned, organized in advance - we cannot simply materialize William Morris' News from Nowhere, nor we cannot return to the soviets - that the future political and economic order must emerge from a contingent historical moment in contact, as it were, with revolutionary practice.

DH: They're dead right, but then we must understand the nature of the moment. This is where cultural analysis is very critical: we must understand how political questions are being disguised by cultural issues. In the United States right now, politics has become impossible, because of the cultural fog in which we are surrounded, and the right wing is deliberately rolling out that fog. Also, we ourselves on the left are enjoying the fog and actually making a lot out of the fog, in my view. So I am very concerned that the left, until it faces the question of what is the political economic transformation that we are after, won't be able to say anything significant politically.

I always liked the distinction between reformists and revolutionaries. In a particular historical moment, in a particular situation, we can both do the same things, reformists and revolutionaries. The difference is that we have a different aim; I always have, in my mind, a long-term goal. So, for instance, when I'm working with a living wage campaign in Baltimore, I know this is a reformist project; I know that the gains to be made from this are relatively trivial in relation to what has to be done in the long run. But I'm still willing to work on it, and am very concerned that we do not give up working on such projects at that level. We have to make our commitments very clear, very strong, even about something as simple as that. At the same time, when I was talking to people on the living wage campaign in Baltimore, I was saying, "well, do you have the ear of the Mayor of Baltimore" - there is something called a Conference of Mayors - "why aren't you actually telling the Mayor to make this...?” And they would do it. Subsequently, living wage campaigns have caught on in all these cities and have gone this way.

So, I think that we're looking for pragmatic shifts right now, we're looking for mitigating effects right now, but what we should have in mind is: which one of these projects or campaigns has the capacity to create an opening towards a grander future? If you loose the idea of a revolutionary project, then actually you've lost politics. I think right now we have a real problem, we've lost politics. I don't know if you know the work of the French philosopher Alain Badiou. He basically says, "we've lost politics and we've got to regain politics," and it's not in terms of what I do at this particular moment that defines whether we are doing politics or not; it's how we are doing it and where we imagine we are headed and how we are going to do it. So we need, I think, a different vision, and that is what concerns me. That different vision, to return to our earlier discussion, is a different political economy. It has to be a different political economy that is the necessary condition for a radical transformation of human relations, absolutely a necessary condition — it's not a sufficient condition, it's a necessary condition

SP: That said, how do you, how does your work engage with social movements? This is a political question, of course, and strikes at the heart of various conceptions of 
"public" — or "organic" or "specific" — intellectuals.

DH: My answer may surprise you ... I value immensely what I learn from working with social movements. But at the same time, if you said, "is it my mission to somehow or other integrate with them?" my answer would be "no.” I think my mission is of a different sort. I am intellectually trained in the ways they are not. Fredric Jameson, for example, is intellectually trained in ways I am not and most of us are not. I think our obligation is to tell it how we see it; it may be entirely wrong, it may be entirely crazy, but until somebody is prepared to stand there and say "given our intellectual training and the fact that I've read political economy in the depth I have, the fact that I've read Marx in the depth I have, and the fact that I've worked in urban history in the way I have, I have an obligation, given those understandings, to tell it how it is." That is how I wrote The Condition of Postmodernity; I took all of my learning and said, "I'm going to use this." That political learning does not exist in the social movements, it exists in my training. Now, one of my big fights within Marxism is that most Marxists do not understand spatiality, space and time, and I think I do. I want people who work in that tradition to understand the importance of uneven geographical development, the importance of urbanisation and environmental dynamics. I want people to have a framework in which they can grasp what is happening to them. You can say this is arrogant, avant-gardist, or whatever you want, but I think that I have an obligation to say it as I see it. In so far as I have had any impact in the world, it's not because of I was some minion involved in this or that; it was because I was prepared in these texts, like The Condition of Postmodernity, to say it as I saw it - given what I knew, part of which came out of the social movements. So I have great respect for what I learned from those social movements, so if you look at a book like Spaces of Hope I could not have written that without the living wage campaign in Baltimore and the social movements. But, on the other hand, they could not have written it either, because they didn't have the equipment. It's like I said to you earlier, we have an obligation, you and I, to magnify what they're saying. Not only magnify it, but turn it into something which is as grand as they want, but on a different scale. I'm very concerned about that. Frankly, I get angry when people somehow or other come at me and say "you're just an academic." I am not interested in that kind of discussion. I am not just an academic: I am an academic, I have worked as an academic, I work in academia, I have skills and I am certainly going to use those skills. I want to practice in a way that opens possibilities. That's what I think my mission can be and I'm passionately committed to that. But a lot of my inspiration comes out of the social movements. If I wasn't connected to social movements, I would not have been able to do the things I've done, I would not have written many of the things I've written. So I'm deeply, deeply indebted to the social movements, but I am not constrained by the idea that somehow or other I have to tell them what they want. No more then I am constrained by the idea that somehow or other I should tell the World Bank what it wants.

SP: Are constrained by the notion that you have to speak for them or with them?

DH: No, I have to speak in a way that is an expansion of what it seems to me their saying and I may misinterpret them and they should call me on it, and they do. When they call me on it, I'm frequently wrong and that's fine, that's how it should be. I need, always, to have the freedom and liberty in my work. 
SP: In my own, limited experience, the one thing that being engaged with social movements teaches academics is to avoid the tendency to imagine the past, present, and future as inactive, inert, finished. Williams' work addresses this question, in Marxism and Literature, for example. One of the things that being involved in social movements have taught me is that the questions we're after, the questions and the problematics that we're after, even some of the so called solutions that we're after, must embrace this conception of social, cultural, political, and economic practices as active and unfinished. This notion came through clearly in your talk today, especially in that wonderful quotation with which you began: "as we make cities, as we imagine spaces in which to live, as we imagine a building that might offer us some certain ensemble tasks, we are imagining and re-imagining, making and remaking ourselves.” To be sure, social movements do not exist to keep academics in check; but the constant pressure keeps one's work active, alive, engaged. To suggest a parallel in my own work, the seventeenth-century writers and thinkers I study and teach were always involved in active struggles - I have Milton in mind, for example. To make the past come alive aesthetically is to make it similarly alive politically.

DH: My favourite line from Balzac is "hope is a memory that desires" and that was how I wrote Spaces of Hope, around that idea. Everybody has a memory, but memory can become nostalgia when it's left on its own; nostalgia is not hope. Hope is memory that's mobilized around desire. So the question is what do we desire and how do we want to desire it? For me, that is the crucial aspect of everything we do. So if I focus on Balzac, to whom I return again and again, I might conclude, "wow, yeah, that's what's it about, I desire things, but I can not do this absent of the memory." As Walter Benjamin says about memory, "memory is not history, its something that flashes up, in moments of danger," it somehow or other animates things. And actually that's where revolutions come from - that is my theory of revolution if you want to put it that way.

Take Ground Zero, for example; it's about a kind of dialectic. What is the memory which is incorporated there now and what desire is going to be connected to it? Actually, what you see is what the authorities want to corral memory into a monument; they wish to memorialize and monumentalize in some way or other. They don't want it to be alive, they want $t$ it to be dead. I want it to be alive.

The most dangerous thing in the world, Benjamin is right, is memory which is not contained in memorialisation, monumentalization, and all the rest of it, he's dead right. Things flash up; I could tell you a little story about this, about when I started to write The New Imperialism, before the invasion of Iraq. On the day of the invasion, I arrived in Madrid with my daughter, then sixteen years old. The first thing we did was to go to the American Embassy; we joined a large demonstration. My daughter quite reasonably said to me, "why did we go to Madrid to go to the American embassy for a demonstration?" I had a hard time explaining it to her; I went back to the hotel, turned on CNN, "shock and awe," and I was outraged because I immediately thought, "Who thinks about the kids?” It's partly because I was there with my kid, but partly because it brought me back to World War II, and the first night of rocket attacks. I was terrified because my mother came in and seized me and threw me under the stairs, so I had been through shock and awe in my childhood and it had a terrible impact on me. I thought, "CNN is reporting all this stuff, how come 
none of them are saying, this must be terrible for the kids in Baghdad?” Who thought about the kids in Baghdad? No one thought about the kids in Baghdad. I was so outraged that I wrote The New Imperialism in six weeks. This was my memory that suddenly came back, about actually being thrown into this cellar from this violent attack, which was completely incomprehensible to my mind and to everyone else around me. Living this moment of danger again, I was thinking about the sheer terror of the invasion of Iraq. I was thinking, "This is not how we should be talking about this event." "Oh, spectacular, the green flashes are going off here and bangs are going off here,” but their kids. I mean how many kids in Iraq lived through this? How many are permanently marked in a way, like I was permanently marked by what happened to me in 1944 ?

I don't know if you remember this thing, but there was this incident where a family was driving and soldiers shot everybody. The soldiers realized they just killed a family and they went and comforted the kids. Your response can only be "what?" This was presented as a story about how good the soldiers were, because they comforted the kids. You say again, “what?” Are those kids going to be grateful to the soldiers for comforting them? What about killing their families? My historical memory about World War II had a very important role in completing that book. I was so angry, I had never written a book so fast and so precisely. Along with hope, anger desires too. 